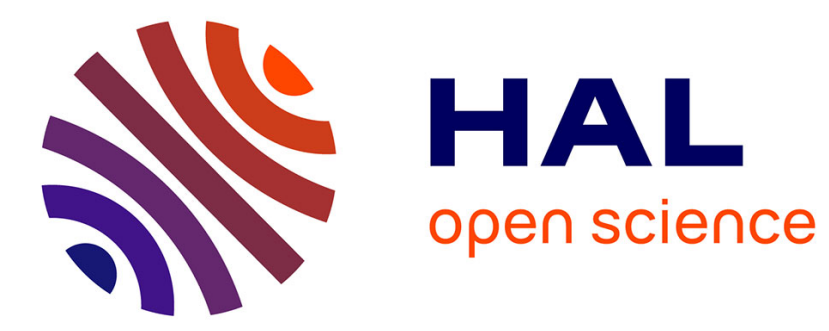

\title{
Atomic-layer deposited thulium oxide as a passivation layer on germanium
}

\author{
I.Z. Mitrovic, S. Hall, M. Althobaiti, D. Hesp, V.R. Dhanak, A. Santoni, A.D.
} Weerakkody, N. Sedghi, P.R. Chalker, C. Henkel, et al.

\section{- To cite this version:}

I.Z. Mitrovic, S. Hall, M. Althobaiti, D. Hesp, V.R. Dhanak, et al.. Atomic-layer deposited thulium oxide as a passivation layer on germanium. Journal of Applied Physics, 2015, 117 (21), pp.214104. 10.1063/1.4922121. hal-01720449

\section{HAL Id: hal-01720449 \\ https://hal.science/hal-01720449}

Submitted on 1 Mar 2018

HAL is a multi-disciplinary open access archive for the deposit and dissemination of scientific research documents, whether they are published or not. The documents may come from teaching and research institutions in France or abroad, or from public or private research centers.
L'archive ouverte pluridisciplinaire HAL, est destinée au dépôt et à la diffusion de documents scientifiques de niveau recherche, publiés ou non, émanant des établissements d'enseignement et de recherche français ou étrangers, des laboratoires publics ou privés. 


\section{Atomic-layer deposited thulium oxide as a passivation layer on germanium}

I. Z. Mitrovic, S. Hall, M. Althobaiti, D. Hesp, V. R. Dhanak, A. Santoni, A. D. Weerakkody, N. Sedghi, P. R.

Chalker, C. Henkel, E. Dentoni Litta, P.-E. Hellström, M. Östling, H. Tan, and S. Schamm-Chardon

Citation: Journal of Applied Physics 117, 214104 (2015); doi: 10.1063/1.4922121

View online: https://doi.org/10.1063/1.4922121

View Table of Contents: http://aip.scitation.org/toc/jap/117/21

Published by the American Institute of Physics

\section{Articles you may be interested in}

Ge interface engineering using ultra-thin $\mathrm{La}_{2} \mathrm{O}_{3}$ and $\mathrm{Y}_{2} \mathrm{O}_{3}$ films: A study into the effect of deposition temperature Journal of Applied Physics 115, 114102 (2014); 10.1063/1.4868091

Atomic layer deposition of $\mathrm{Nb}$-doped $\mathrm{ZnO}$ for thin film transistors Applied Physics Letters 109, 222103 (2016); 10.1063/1.4968194

The role of nitrogen doping in ALD $\mathrm{Ta}_{2} \mathrm{O}_{5}$ and its influence on multilevel cell switching in RRAM Applied Physics Letters 110, 102902 (2017); 10.1063/1.4978033

Conduction band offset at $\mathrm{GeO}_{2} / \mathrm{Ge}$ interface determined by internal photoemission and charge-corrected x-ray photoelectron spectroscopies

Applied Physics Letters 102, 102106 (2013); 10.1063/1.4794417

High- $\kappa$ gate dielectrics: Current status and materials properties considerations

Journal of Applied Physics 89, 5243 (2001); 10.1063/1.1361065

Evidence of low interface trap density in $\mathrm{GeO}_{2} / \mathrm{Ge}$ metal-oxide-semiconductor structures fabricated by thermal oxidation

Applied Physics Letters 93, 032104 (2008); 10.1063/1.2959731

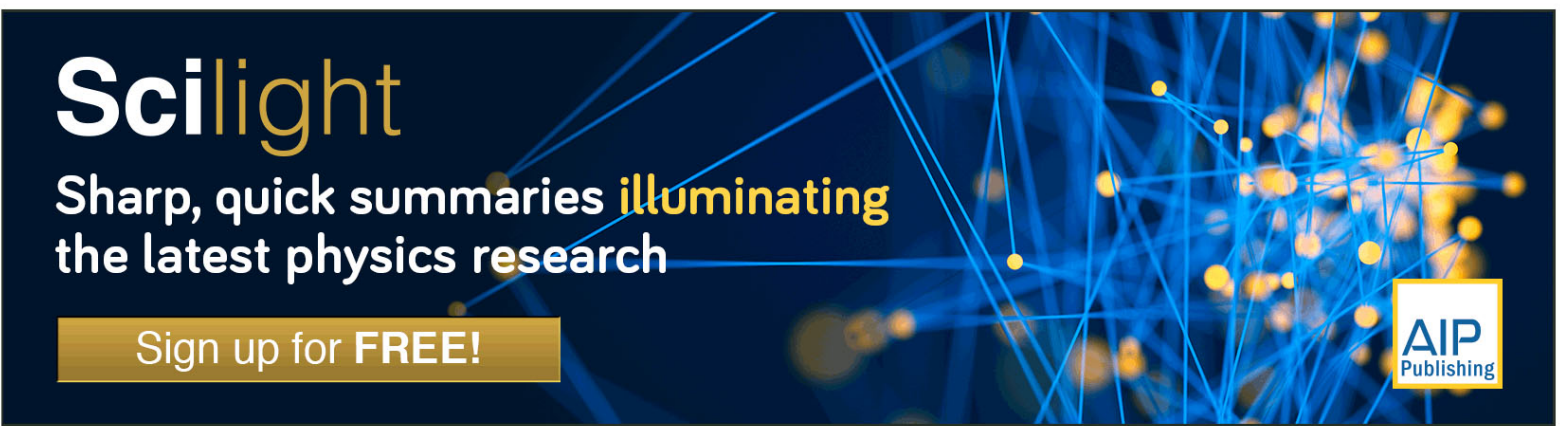




\title{
Atomic-layer deposited thulium oxide as a passivation layer on germanium
}

\author{
I. Z. Mitrovic, ${ }^{1, a)}$ S. Hall, ${ }^{1}$ M. Althobaiti, ${ }^{2}$ D. Hesp, ${ }^{2}$ V. R. Dhanak, ${ }^{2}$ A. Santoni, ${ }^{3}$ \\ A. D. Weerakkody, ${ }^{1}$ N. Sedghi, ${ }^{1}$ P. R. Chalker, ${ }^{4}$ C. Henkel, ${ }^{5, b)}$ E. Dentoni Litta, ${ }^{5}$ \\ P.-E. Hellström, ${ }^{5}$ M. Östling, ${ }^{5}$ H. Tan, ${ }^{6}$ and S. Schamm-Chardon ${ }^{6}$ \\ ${ }^{1}$ Department of Electrical Engineering and Electronics, University of Liverpool, Brownlow Hill, \\ Liverpool L69 3GJ, United Kingdom \\ ${ }^{2}$ Department of Physics and Stephenson Institute for Renewable Energy, University of Liverpool, \\ Liverpool L69 7ZF, United Kingdom \\ ${ }^{3}$ ENEA, Frascati Research Centre, via E. Fermi 45, 00044 Frascati, Italy \\ ${ }^{4}$ Department of Engineering, University of Liverpool, Brownlow Hill, Liverpool L69 3GH, United Kingdom \\ ${ }^{5}$ School of ICT, KTH Royal Institute of Technology, Isafjordsgatan 22, 16440 Kista, Sweden \\ ${ }^{6}$ CEMES-CNRS and Université de Toulouse, nMat group, BP 94347, 31055 Toulouse Cedex 4, France
}

(Received 10 December 2014; accepted 23 May 2015; published online 3 June 2015)

\begin{abstract}
A comprehensive study of atomic-layer deposited thulium oxide $\left(\mathrm{Tm}_{2} \mathrm{O}_{3}\right)$ on germanium has been conducted using x-ray photoelectron spectroscopy (XPS), vacuum ultra-violet variable angle spectroscopic ellipsometry, high-resolution transmission electron microscopy (HRTEM), and electron energy-loss spectroscopy. The valence band offset is found to be $3.05 \pm 0.2 \mathrm{eV}$ for $\mathrm{Tm}_{2} \mathrm{O}_{3} / \mathrm{p}-\mathrm{Ge}$ from the Tm $4 d$ centroid and Ge $3 p_{3 / 2}$ charge-corrected XPS core-level spectra taken at different sputtering times of a single bulk thulium oxide sample. A negligible downward band bending of $\sim 0.12 \mathrm{eV}$ is observed during progressive differential charging of Tm $4 \mathrm{~d}$ peaks. The optical band gap is estimated from the absorption edge and found to be $5.77 \mathrm{eV}$ with an apparent Urbach tail signifying band gap tailing at $\sim 5.3 \mathrm{eV}$. The latter has been correlated to HRTEM and electron diffraction results corroborating the polycrystalline nature of the $\mathrm{Tm}_{2} \mathrm{O}_{3}$ films. The $\mathrm{Tm}_{2} \mathrm{O}_{3} /$ Ge interface is found to be rather atomically abrupt with sub-nanometer thickness. In addition, the band line-up of reference $\mathrm{GeO}_{2} / \mathrm{n}$-Ge stacks obtained by thermal oxidation has been discussed and derived. The observed low reactivity of thulium oxide on germanium as well as the high effective barriers for holes $(\sim 3 \mathrm{eV})$ and electrons $(\sim 2 \mathrm{eV})$ identify $\mathrm{Tm}_{2} \mathrm{O}_{3}$ as a strong contender for interfacial layer engineering in future generations of scaled high- $\kappa$ gate stacks on Ge. (C) 2015 AIP Publishing LLC.

[http://dx.doi.org/10.1063/1.4922121]
\end{abstract}

\section{INTRODUCTION}

Interface engineering plays a pivotal role in new high- $\kappa /$ metal gate technology advancement. ${ }^{1}$ Germanium has recently gained much interest as a high carrier mobility channel substitute to silicon in complementary metal oxide semiconductor (CMOS) devices together with the use of high- $\kappa$ dielectric materials, such as $\mathrm{HfO}_{2} \cdot{ }^{2,3}$ In contrast to superior interface properties of $\mathrm{SiO}_{2} / \mathrm{Si}$, Ge oxides are wellknown to be thermally and chemically unstable. ${ }^{4}$ Therefore, passivation of the Ge surface is a critical step for fabricating high performance Ge-based field effect transistors (FETs). The native oxide $\mathrm{GeO}_{2}$ has attracted renewed research interest $^{5}$ as a potential passivation layer owing to its excellent interface control on Ge. However, for aggressive oxide scaling with equivalent oxide thickness (EOT) well below $1 \mathrm{~nm}$, the combination of higher- $\kappa$ rare-earth (RE) oxide and ultrathin $\mathrm{GeO}_{2}$ is required..$^{6}$ The thermodynamically robust interfacial layer (IL) engineering on $\mathrm{Ge}$ using $\mathrm{RE} \mathrm{Y}_{2} \mathrm{O}_{3}$-doped $\mathrm{GeO}_{2}$ has been shown recently to deliver $0.47 \mathrm{~nm}$ EOT on $\mathrm{Ge}$, with superior interface properties and mobilities in Ge nMOSFETs. ${ }^{6}$ Another approach to achieving sub-nm EOT Ge gate stacks is utilizing $\mathrm{Al}_{2} \mathrm{O}_{3}$ barrier IL properties. ${ }^{2,3,7}$

\footnotetext{
a) Author to whom correspondence should be addressed. Electronic mail: ivona@liverpool.ac.uk.

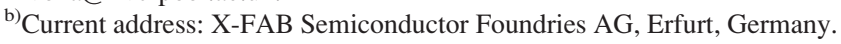

Rare-earth thulium oxide $\left(\mathrm{Tm}_{2} \mathrm{O}_{3}\right)$ has been considered as the main high-k dielectric ${ }^{8}$ and as a capping layer for $\mathrm{La}_{2} \mathrm{O}_{3}$ based gate stacks, ${ }^{9}$ but only on $\mathrm{Si}$. A low reactivity of $\mathrm{Tm}_{2} \mathrm{O}_{3}$ with the $\mathrm{Si}$ substrate has been observed. ${ }^{10}$ There have been theoretical prediction and some recent estimations of the band gap $\left(\sim 5 \mathrm{eV},{ }^{11} \sim 6.5 \mathrm{eV},{ }^{12}\right.$ and $5.76 \mathrm{eV},{ }^{13}$ respectively) on $\mathrm{Tm}_{2} \mathrm{O}_{3} / \mathrm{Si}$ structures. Atomic-layer deposition (ALD) has become one of the preferred methods for thin film deposition in several fields due to the excellent thickness control, uniformity, and conformality. A novel process for atomic-layer deposition of thulium oxide has been recently developed. ${ }^{14}$ A TmSiO IL layer with EOT of $\sim 0.25 \mathrm{~nm}$ has been achieved, which indicates a strong potential for its integration in sub-10 $\mathrm{nm}$ technology nodes. ${ }^{15}$ Conversely, there have been no reports on $\mathrm{Tm}_{2} \mathrm{O}_{3}$ as a passivation layer on $\mathrm{Ge}$, apart from our earlier work. ${ }^{16}$

A reliable measurement method to determine the band offsets is essential for modelling the carrier transport properties. The offsets reported at the $\mathrm{GeO}_{2} / \mathrm{Ge}$ interface show large scattering in the range of about $1 \mathrm{eV}$ for data obtained by $\mathrm{x}$-ray photoelectron spectroscopy (XPS) and internal photoemission (IPE) (see Ref. 17 and references therein). Detailed mechanism responsible for such discrepancy is not clear. There are assumptions made that this is due to different $\mathrm{GeO}_{2}$ growth methods. ${ }^{5,18-23}$ Furthermore, it has come recently to focus that the XPS requires careful attention to 
charging effects as a result of electron emission from the insulator; ${ }^{24-26}$ while the IPE data demand careful interpretation. ${ }^{27}$ A clear understanding of the physical phenomena behind the charge accumulation and neutralization in dielectric/semiconductor heterojunction during XPS measurements seems still to be elusive. ${ }^{25}$ A recent XPS study on $\mathrm{HfO}_{2} / \mathrm{Ge}$ heterostructures ${ }^{28}$ suggests that the role of germanium is not negligible in the neutralization mechanisms beyond the differential charging effect. Charging can occur in an XPS experiment when the holes that are created by the ejection of photoelectrons accumulate in a sample. This build-up of charge results in an increase in the binding energy (BE) of spectral features. Bersch et al. ${ }^{26}$ have shown that not correcting for charging results in overestimation of valence band offset (VBO) by $\sim 0.5 \mathrm{eV}$ on average. It is common practice for the VBO to be determined from XPS measurements by Kraut's method using the valence band (VB) and core-level (CL) photoemission from bulk-like samples of the two constituent materials and a thin interfacial sample forming the interface of interest. ${ }^{29}$ The overlayer of this heterojunction sample must be sufficiently thin (usually $<5 \mathrm{~nm}$ ) to allow XPS core-levels from the underlying material to be probed due to the finite escape depth of the photoelectrons. The binding energy values are referenced to the valence band maximum (VBM) of each sample, determined by extrapolating a linear fit of the leading edge of the VB photoemission to the baseline in order to account for broadening of the photoemission spectra. ${ }^{30}$ Then, the VBO for oxide/semiconductor substrate sample can be determined as

$$
\mathrm{VBO}=\delta_{\mathrm{SUB}}+\delta_{\mathrm{INT}}-\delta_{\mathrm{OXIDE}}
$$

where $\delta_{\text {SUB }}$ and $\delta_{\text {OXIDE }}$ are the energy differences between chosen reference core-levels in substrate and bulk oxide samples and their respective VBMs, while $\delta_{\text {INT }}$ refers to the BE difference for the former two core-levels for the interfacial sample.

This paper conveys three important findings: (i) the valence band offset for $\mathrm{Tm}_{2} \mathrm{O}_{3} / \mathrm{Ge}$ of $3.05 \pm 0.2 \mathrm{eV}$, determined by Kraut's method ${ }^{29}$ using a single sample consequently sputtered with core-level spectra taken at different sputtering times, shows consistency within experimental error with the offset result obtained using three distinctive samples (bulk, interfacial, and substrate) ${ }^{16}$ (ii) the VBO for thermal $\mathrm{GeO}_{2} / \mathrm{Ge}$ is in agreement with the most recent report from Toriumi's group ${ }^{17}$ substantiating a conduction band offset (CBO) higher than $1 \mathrm{eV}$ and the appropriateness of $\mathrm{GeO}_{2}$ use in passivation of $\mathrm{Ge}$; (iii) $\mathrm{Tm}_{2} \mathrm{O}_{3}$ shows even lower reactivity on $\mathrm{Ge}$ than on $\mathrm{Si}$, with rather atomically sharp interface indicating possible barrier properties.

\section{EXPERIMENTAL}

The $10 \mathrm{~nm}$ (nominal) thick $\mathrm{Tm}_{2} \mathrm{O}_{3}$ samples were prepared by ALD on $35 \mathrm{~nm}$ p-Ge epitaxial layer/Si(100) and on $\mathrm{Si}(100)$. The reference samples of $\mathrm{GeO}_{2}$ (5 and $10 \mathrm{~nm}$ nominal thicknesses) were grown on $35 \mathrm{~nm} n-\mathrm{Ge}$ epi/Si(100) by thermal oxidation at $525^{\circ} \mathrm{C}$ under $1 \mathrm{~atm} \mathrm{O}_{2}$. Prior to the gate oxide deposition, epi $\mathrm{Ge} / \mathrm{Si}(100)$ samples were cleaned in a $\mathrm{HF} 0.5 \%$ /Isopropanol $1 \% / \mathrm{H}_{2} \mathrm{O}$ mixture to remove (minimize) the native Ge oxide layer. The $\mathrm{Tm}_{2} \mathrm{O}_{3}$ layers were deposited using Tris(cyclopentadienyl)thulium, heated to $140{ }^{\circ} \mathrm{C}$, and water vapor as precursor gases. ${ }^{14}$ An ultra-high vacuum (UHV) system operating at $4 \times 10^{-8} \mathrm{~Pa}$ base pressure and equipped with a VG $\mathrm{Al} \mathrm{K} \alpha$ monochromatized $\mathrm{x}$-ray source and a CLAM2 hemispherical analyzer was used for XPS data acquisition at normal emission. The electron analyzer was set at constant $20 \mathrm{eV}$ pass energy mode and calibrated. ${ }^{31}$ The total energy resolution is found to be $<0.7 \mathrm{eV}$ from the fitting of the Fermi edge of a clean Au sample. The binding energy is referred to the position of the Fermi level measured on a clean Ta strip in good electrical contact with the sample. In order to reach the $\mathrm{Tm}_{2} \mathrm{O}_{3} / \mathrm{Ge}$ interface, the samples were mildly sputtered with $0.5 \mathrm{keV} \mathrm{Ar}^{+}$ion energy $(0.25 \mathrm{~nm} / \mathrm{min})$. The main XPS core-levels and VB edge in the bulk $\mathrm{Tm}_{2} \mathrm{O}_{3}$ have been monitored as a function of sputtering time in order to reveal possible sputtering-induced effects. No change in the VB edge positions and in the Tm $4 \mathrm{~d}$ and $\mathrm{O}$ 1s CL lineshapes, relative intensities, and BE positions could be detected by XPS after sputtering cycles, indicating that $\mathrm{Ar}^{+}$bombardment did not induce preferential sputtering and any observable surface modifications. The XPS spectra for $\mathrm{GeO}_{2} / \mathrm{n}$-Ge samples were recorded on a separate UHV system consisting of an $\mathrm{Al} \mathrm{K} \alpha \mathrm{x}$-ray $(\mathrm{h} \nu=1486.6 \mathrm{eV})$ source and a PSP Vacuum Technology electron energy analyzer. This spectrometer was calibrated so the $\mathrm{Ag} 3 \mathrm{~d}_{5 / 2}$ photoelectron line had a BE of $368.35 \mathrm{eV}$, a full width at half maximum (FWHM) of $0.8 \mathrm{eV}$ being the spectral resolution for this study, and a $10 \mathrm{eV}$ pass energy. Charge compensation was achieved using a VG Scienta FG300 low energy electron flood gun with the gun settings adjusted for optimal spectral resolution. The electron BEs were then corrected by setting the $\mathrm{C} 1 \mathrm{~s}$ peak in the spectra (due to stray carbon impurities) at $284.6 \mathrm{eV}$ for all samples. ${ }^{32}$ The probe area during the XPS measurements was $1 \mathrm{~mm}^{2}$. The error bar $( \pm 0.2 \mathrm{eV})$ we defined in this paper is due to VBM determination through the linear interpolation method. ${ }^{30}$ The core-level binding energy determination by fitting a Voigt curve to a measured peak introduces typically much smaller $( \pm 0.05 \mathrm{eV})$ error. A Shirley-type background ${ }^{33}$ is used during the fitting of all spectra. The vacuum ultra-violet variable angle spectroscopic ellipsometry (VUV-VASE) measurements were performed using a spectral range from 0.5 to $8 \mathrm{eV}$, and the angles of incidence of $55^{\circ}-75^{\circ}$, by $10^{\circ}$ as a step, to maximize the accuracy. The atomic structure and elemental analysis were investigated with high-resolution transmission electron microscopy (HRTEM) and electron energy-loss spectroscopy (EELS) performed on a field emission image-corrected FEI Tecnai $^{\text {TM }}$ F20 microscope operating at $200 \mathrm{kV}$. For local EELS studies, the microscope was also equipped with a scanning stage (STEM), allowing a focused one nanometer-sized probe to be scanned over the sample area of interest (in our case, a line crossing the $\mathrm{Tm}_{2} \mathrm{O}_{3} / \mathrm{Ge}$ interface), and an imaging filter (Gatan GIF TRIDIEM) used as a spectrometer.

\section{RESULTS AND DISCUSSION}

\section{A. Estimation of VBO for $\mathrm{Tm}_{2} \mathrm{O}_{3} / \mathrm{Ge}$ gate stack}

The VBO determination of the $\mathrm{Tm}_{2} \mathrm{O}_{3} / \mathrm{Ge}$ system is addressed first. Fig. 1 shows high-resolution Tm 4d, valence 
band and Ge 3p XPS spectra taken at three different sputtering times referring to bulk $\mathrm{Tm}_{2} \mathrm{O}_{3}$ (Figs. 1(a) and 1(b)), interface (Figs. 1(c) and 1(d)) and Ge substrate (Figs. 1(e) and 1(f)). Since for Ge 3d, a strong presence of neighboring $\mathrm{O} 2 \mathrm{~s}$ and Tm $5 \mathrm{p}$ doublet complicates the interpretation of the spectra, ${ }^{16}$ in this work, Ge $3 \mathrm{p}_{3 / 2}$ and the centroid value of $\mathrm{Tm}$ 4d core-levels were used for VBO estimation. Figure 2(a) shows the peak areas of two components of $\mathrm{O} 1 \mathrm{~s}$ corelevel: from the main $\mathrm{Tm}_{2} \mathrm{O}_{3}$ (circle symbol) and from IL (triangle symbol). Each symbol point on the graphs refers to a single sputtering time, when the spectrum was taken. At first, the signal is dominated by the thulium contribution (until $\sim 1100 \mathrm{~s}$ ); however, as the sputtering through the film continues, the IL becomes more prominent until only interfacial layer species are left (at $\sim 2000 \mathrm{~s}$ ). These changes are further reflected in the plot of the Auger parameter, also shown in Fig. 2(a). The Auger parameter was calculated using the centroid values of the $\mathrm{O} 1 \mathrm{~s}$ peak and from the O KLL Auger peak. ${ }^{34}$ Note that in interfacial $\mathrm{Tm}_{2} \mathrm{O}_{3} / \mathrm{Ge}$ heterostructures, the Tm 4d core-levels exhibit a monotonically decreasing shift towards lower BEs of $\sim 0.12 \mathrm{eV}$ when sputtering $\mathrm{Tm}_{2} \mathrm{O}_{3}$ film (Figs. 1(c) and 2(b)), thus providing clear fingerprints of charging phenomenon. ${ }^{25,26}$ On the contrary, a very small variation $(\sim 0.05 \mathrm{eV})$ of the Ge $3 p$ BEs was observed
(Figs. 1(d) and 2(c)). To account for the effect of differential charging, the positions of $\mathrm{Tm} 4 \mathrm{~d}$ and Ge $3 \mathrm{p}$ peaks were estimated by extrapolating the measured BEs to zero $\mathrm{Tm}_{2} \mathrm{O}_{3}$ thickness (i.e., to the highest value of sputtering time in our experiment, see Fig. 2(a)), and hence ideally to zero charge. $^{25}$ The difference of $\mathrm{Tm} 4 \mathrm{~d}$ and $\mathrm{O}$ 1s peaks was found to be $354.29 \pm 0.03 \mathrm{eV}$, being indicative of the same stoichiometry of the films sputtered $<2000 \mathrm{~s}$. The value Tm $4 \mathrm{~d}-$ Ge $3 \mathrm{p}_{3 / 2}=\delta_{\mathrm{INT}}=54.89 \mathrm{eV}$ was extracted from the extrapolated values in Figs. 2(b) and 2(c). Comparing the Ge $3 p_{3 / 2}$ peak of the Ge substrate and the same peak with $\mathrm{Tm}_{2} \mathrm{O}_{3}$ on top, an energy shift towards higher BEs of $0.06 \mathrm{eV}$ is observed. This is a signature of a small downward band bending, which agrees with the presence of p-type Ge. ${ }^{35}$ The result suggests negligible bending of Ge core-levels despite the charging of the $\mathrm{Tm}_{2} \mathrm{O}_{3}$ film during X-ray exposure; a converse scenario has been observed for $\mathrm{HfO}_{2} / \mathrm{n}-\mathrm{Ge}^{28}$ The $\mathrm{BE}$ differences between Tm 4d centroid and VBM for bulk $\mathrm{Tm}_{2} \mathrm{O}_{3}\left(\delta_{\text {OXIDE }}\right)$, and $\mathrm{Ge} 3 \mathrm{p}_{3 / 2}$ and VBM for the Ge substrate $\left(\delta_{\mathrm{SUB}}\right)$ measured from Figs. 1(a) and 1(b) and Figs. 1(e) and $1(\mathrm{f})$, respectively, are summarized in Table I. By inserting $\delta_{\text {OXIDE }}, \delta_{\text {INT }}, \delta_{\text {SUB }}$ values in Kraut's equation (1), the $\mathrm{VBO}=\delta_{\mathrm{SUB}}+\delta_{\mathrm{INT}}-\delta_{\mathrm{OXIDE}}=3.05 \pm 0.2 \mathrm{eV}$ is calculated for $\mathrm{Tm}_{2} \mathrm{O}_{3} / \mathrm{Ge}$. The result is in agreement with our

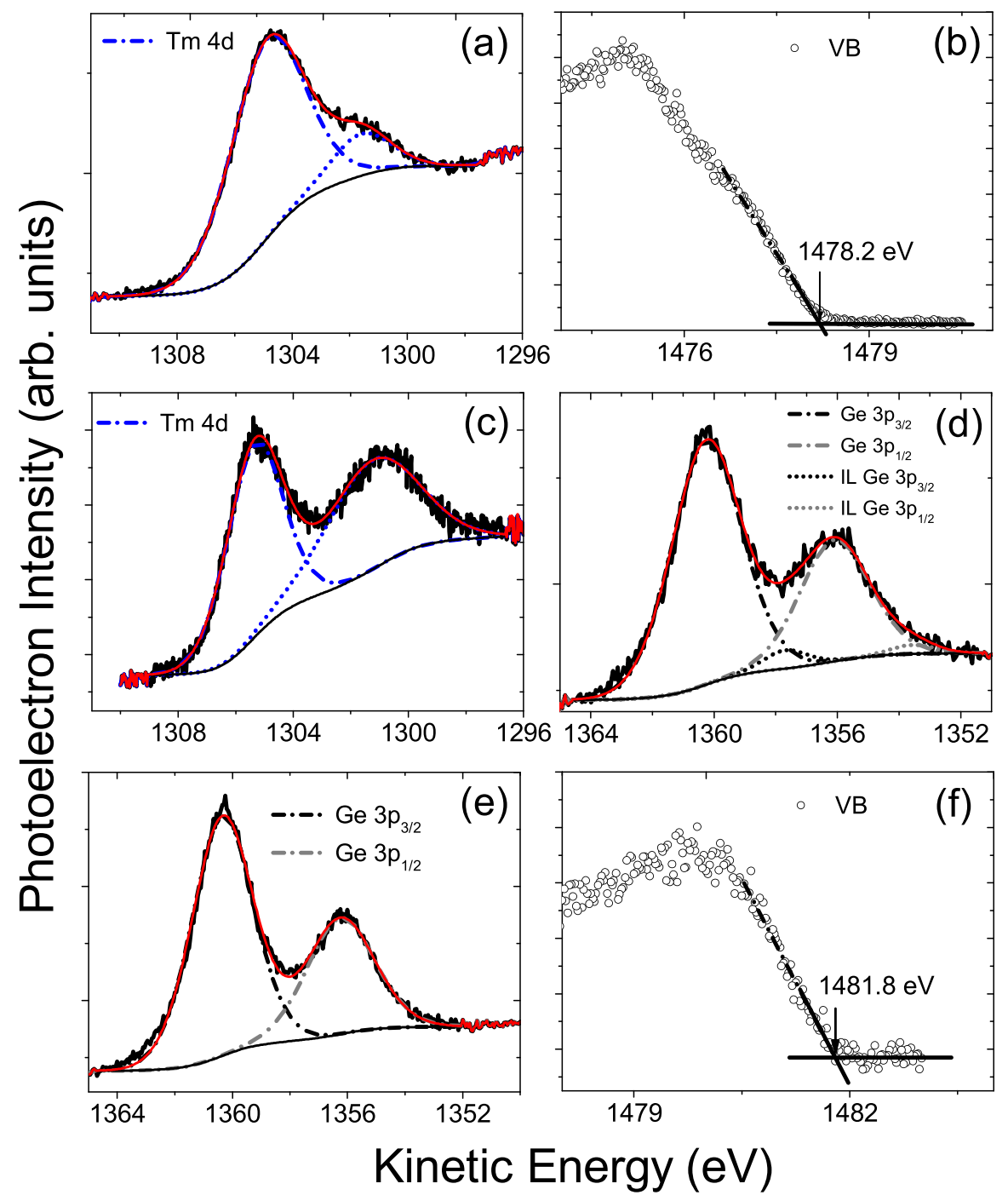

FIG. 1. Shallow core-levels and VB spectra for a bulk $\mathrm{Tm}_{2} \mathrm{O}_{3} / \mathrm{Ge}$ (a) and (b), an interfacial $\mathrm{Tm}_{2} \mathrm{O}_{3} / \mathrm{Ge}$ (c) and (d), and Ge substrate (e) and (f), recorded after sputtering for $210 \mathrm{~s}$, $1470 \mathrm{~s}$, and $2190 \mathrm{~s}$, respectively. There is an additional peak (with spin-orbit splitting) for Ge $3 p$ fitting in (d) due to IL contribution. 

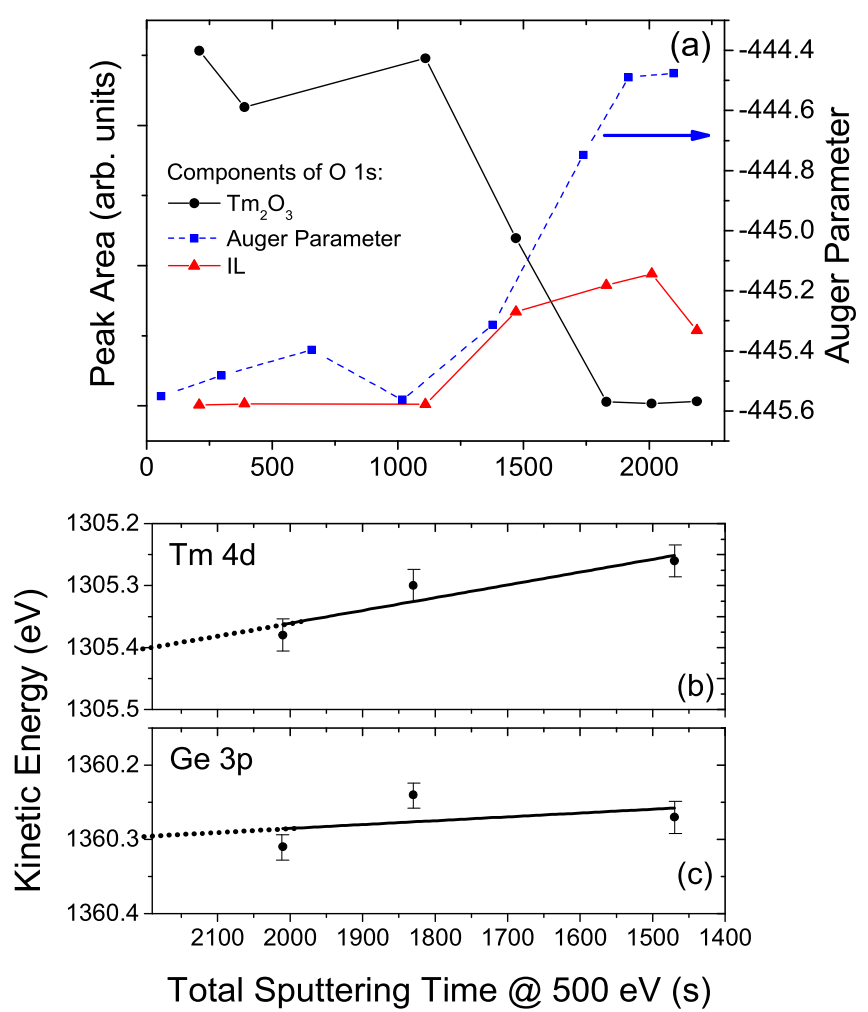

FIG. 2. (a) The peak area of the components of O 1s XPS core-level (left) and Auger parameter (right) as a function of total sputtering time. (b) and (c) The extrapolation of charge-corrected kinetic energies of $\mathrm{Tm} 4 \mathrm{~d}$ and $\mathrm{Ge} 3 \mathrm{p}_{3 / 2}$ core-levels.

previously reported value of $2.95 \pm 0.08 \mathrm{eV}^{16}$ from the XPS measurements taken on three distinctive samples.

\section{B. Estimation of $\mathrm{VBO}$ for $\mathrm{GeO}_{2} / \mathrm{Ge}$ gate stack}

We now look to the estimation of VBO for the reference $\mathrm{GeO}_{2} / \mathrm{Ge}$ system. Figs. 3(a) and 3(b) show high-resolution Ge $3 \mathrm{~d}$ core-levels taken for bulk and interfacial $\mathrm{GeO}_{2} / \mathrm{Ge}$ after prolonged (at least an hour) $\mathrm{x}$-ray exposure, until the point they reached constant BEs. ${ }^{17,25,26}$ The $\mathrm{GeO}_{2}$ film shows two main peaks, fitted to doublets of Voigt functions with spin orbit splitting of $0.6 \mathrm{eV}$ and branching ratio [1/2]. The difference between $\mathrm{Ge} 3 \mathrm{~d}_{5 / 2}$ of the substrate $(28.95 \mathrm{eV})$ and $\mathrm{GeO}_{2}$ $(32.34 \mathrm{eV})$ for the bulk sample is $3.4 \mathrm{eV}$, showing a stoichiometric $\mathrm{GeO}_{2}$ and negligible differential charging. ${ }^{17,36}$
Comparing the Ge $3 \mathrm{~d}_{5 / 2}$ peak of the bare Ge (not shown) and the same peak from Ge with $\mathrm{GeO}_{2}$ on top (Fig. 3(a)), an energy shift of $0.05 \mathrm{eV}$ towards lower BEs is observed. The shift is consistent with $\mathrm{n}-\mathrm{Ge}^{20}$ and implies a $0.05 \mathrm{eV}$ upward band bending at the $\mathrm{GeO}_{2} / \mathrm{n}$-Ge interface, in agreement with the formation of a superficial p-inversion layer in the n-type Ge substrates. ${ }^{37}$ Note in Fig. 3(a) that the peak at $\sim 23 \mathrm{eV}$ refers to $\mathrm{O} 2 \mathrm{~s} \mathrm{CL}$, while three minor peaks in the energy range from 5 to $15 \mathrm{eV}$ are part of $\mathrm{VB}$ and relate to $\mathrm{O} 2 \mathrm{p}, \mathrm{Ge} 4 \mathrm{~s}$, and Ge $4 p$ species in agreement with the literature. ${ }^{20}$ The measured $\mathrm{BE}$ differences, $\delta_{\mathrm{OXIDE}}, \delta_{\mathrm{INT}}$, and $\delta_{\mathrm{SUB}}$, for $\mathrm{GeO}_{2} / \mathrm{Ge}$ are listed in Table I and the literature values ${ }^{17,20,28,38}$ are also inserted for comparison. Applying Kraut's equation (1), yields a $\mathrm{VBO}=\delta_{\text {SUB }}+\delta_{\text {INT }}-\delta_{\text {OXIDE }}=3.55 \pm 0.2 \mathrm{eV}$, consistent with a value of $3.6 \pm 0.2 \mathrm{eV}$ reported by $\mathrm{XPS}^{17}$ and by synchrotron radiation photoemission spectroscopy. ${ }^{5}$

\section{Band gap evaluation and nature of $\mathrm{Tm}_{2} \mathrm{O}_{3} / \mathrm{Ge}$ interface}

The band gaps of $\mathrm{Tm}_{2} \mathrm{O}_{3}$ and $\mathrm{GeO}_{2}$ were determined by VUV-VASE. This was accomplished by first determining the thickness in the non-absorbing (transparent) region of the spectra. The dielectric function of the Ge film $(31.9 \mathrm{~nm})$ with the native oxide as Cauchy layer $(1.4 \mathrm{~nm})$ was modeled first. Then, another Cauchy layer is added and fitted for the thickness of $\mathrm{Tm}_{2} \mathrm{O}_{3}$ film $(10.4 \mathrm{~nm})$ or $\mathrm{GeO}_{2} \quad(4.6 \mathrm{~nm})$. Subsequently, the optical constants (real and imaginary part of dielectric function) were extracted. The $\mathrm{Tm}_{2} \mathrm{O}_{3}\left(\mathrm{GeO}_{2}\right)$ film was modelled with Cauchy layer at long wavelengths and extended into VUV with the B-spline and then converted to a general oscillator layer. The dielectric function converts to refractive index and extinction coefficient (k) using Kramers-Kronig relations. The absorption coefficient $(\alpha)$ is calculated from the extinction coefficient as $\alpha=4 \pi \mathrm{k} / \lambda$, where $\lambda$ is wavelength. The absorption coefficient vs photon energy plots for $\mathrm{GeO}_{2} / \mathrm{Ge}$ and $\mathrm{Tm}_{2} \mathrm{O}_{3} / \mathrm{Ge}$ stacks are shown in Figs. 3(c) and 3(d), respectively. The band gap can be estimated by linear extrapolation of the segments on the curves in the non-absorbing regions, and is found to be $5.95 \mathrm{eV}$ for $\mathrm{GeO}_{2}$ and $5.77 \mathrm{eV}$ for $\mathrm{Tm}_{2} \mathrm{O}_{3}$. The schematics of derived band line-ups for $\mathrm{GeO}_{2} / \mathrm{Ge}$ and $\mathrm{Tm}_{2} \mathrm{O}_{3} / \mathrm{Ge}$ are depicted in Figs. 3(e) and 3(f). Note that both band gap values are slightly higher than those reported using the Tauc-Lorentz

TABLE I. Summary of XPS core-level energy differences measured for $\mathrm{Tm}_{2} \mathrm{O}_{3} / \mathrm{Ge}$ and $\mathrm{GeO}_{2} / \mathrm{Ge}$ samples in this work and from the literature ${ }^{17,20,28,38}$ with derived values of VBO and optical band gap.

\begin{tabular}{|c|c|c|c|c|}
\hline \multirow[b]{2}{*}{$\delta_{\text {OXIDE }}(\mathrm{eV})$} & \multicolumn{2}{|c|}{$\mathrm{Tm}_{2} \mathrm{O}_{3} / \mathrm{p}-\mathrm{Ge}$} & \multicolumn{2}{|c|}{$\mathrm{GeO}_{2} / \mathrm{n}-\mathrm{Ge}$} \\
\hline & $\mathrm{Tm}^{4 \mathrm{~d}}-\mathrm{VBM}$ & 173.32 & $\mathrm{Ge}^{3 \mathrm{~d} \mathrm{GeO} 2}-\mathrm{VBM}$ & 29.56 and $28.58^{\mathrm{b}}$ \\
\hline$\delta_{\text {INT }}(\mathrm{eV})$ & $\mathrm{Tm}^{4 \mathrm{~d}}-\mathrm{Ge}^{3 \mathrm{p}}$ & 54.89 & $\mathrm{Ge}^{3 \mathrm{~d} \mathrm{GeO} 2}-\mathrm{Ge}^{3 \mathrm{~d} \text { sub }}$ & 3.59 and $3.6^{\mathrm{b}}$ \\
\hline \multirow[t]{2}{*}{$\delta_{\text {SUB }}(\mathrm{eV})$} & $\mathrm{Ge}^{3 \mathrm{p}}-\mathrm{VBM}$ & 121.48 & & \\
\hline & $\mathrm{Ge}^{3 \mathrm{~d}}-\mathrm{VBM}$ & $29.32,29.30^{\mathrm{a}}$ & $\mathrm{Ge}^{3 \mathrm{~d}}-\mathrm{VBM}$ & $29.52,29.47,{ }^{\mathrm{b}} 29.31,{ }^{\mathrm{c}}$ and $29.36-29.58^{\mathrm{d}}$ \\
\hline VBO $(e V)$ & 3.05 & & 3.55 & \\
\hline Eg $(\alpha$-method $)(e V)$ & 5.77 & & 5.95 & \\
\hline
\end{tabular}

${ }^{\mathrm{a}}$ Ref. 17.

${ }^{\mathrm{b}}$ Ref. 20.

${ }^{\mathrm{c}}$ Ref. 28.

${ }^{\mathrm{d}}$ Ref. 38. 

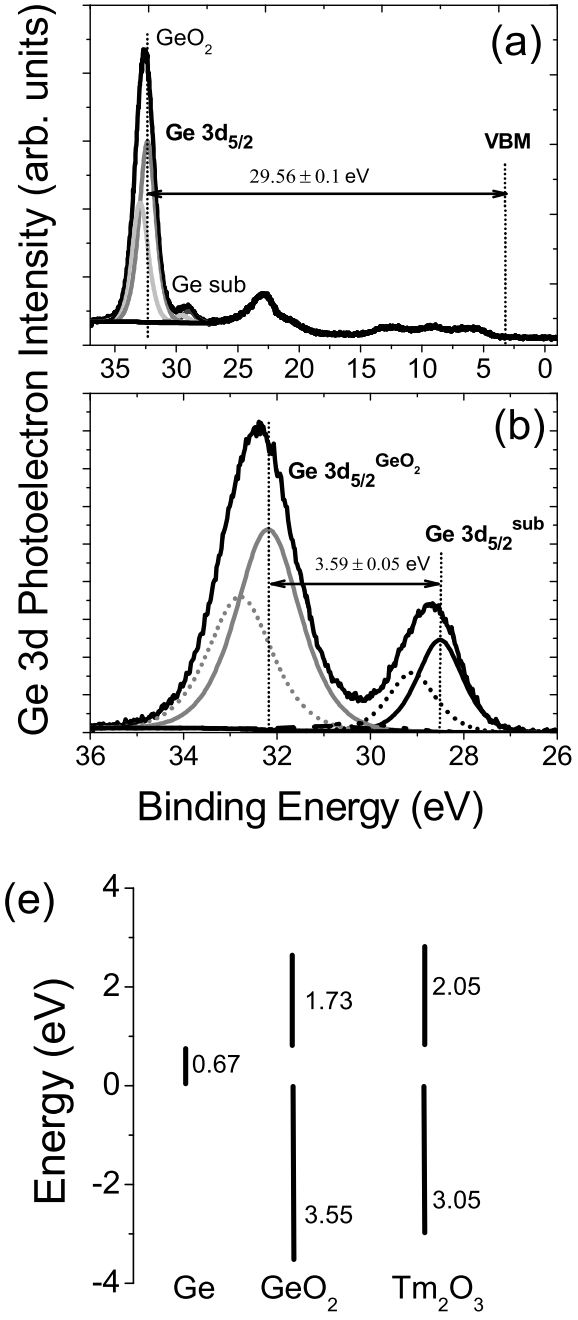

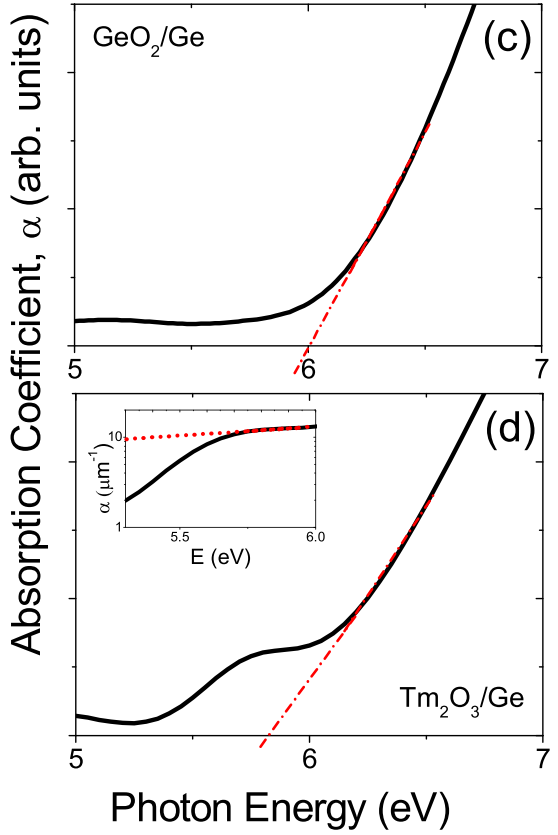

(f)
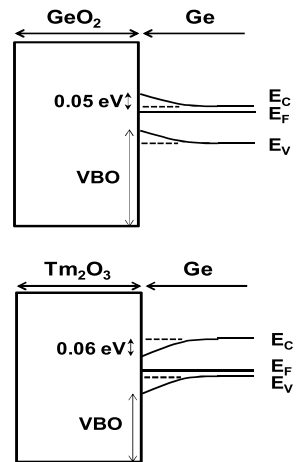

FIG. 3. The experimental and fitted Ge $3 \mathrm{~d}$ XPS core-levels for (a) a thick $10 \mathrm{~nm}$ $\mathrm{GeO}_{2} / \mathrm{Ge}$, and (b) a thin $5 \mathrm{~nm} \mathrm{GeO} / \mathrm{Ge}$. VBM refers to valence band maximum. Absorption coefficient vs photon energy extracted from VUV-VASE data for: (c) $\mathrm{GeO}_{2} / \mathrm{Ge}$ and (d) $\mathrm{Tm}_{2} \mathrm{O}_{3} / \mathrm{Ge}$. (e) The schematic of measured band gaps and hole barrier heights, where electron barrier heights, i.e., $\mathrm{CBO}$ is calculated using $\mathrm{CBO}=\mathrm{E}_{\mathrm{g}(\mathrm{OXIDE})}-\mathrm{VBO}-\mathrm{E}_{\mathrm{g}(\mathrm{Ge})}$, where $E_{g}$ refers to the band gap. (f) The schematic of experimentally observed band bending for $\mathrm{GeO}_{2} / \mathrm{n}-\mathrm{Ge}$ and $\mathrm{Tm}_{2} \mathrm{O}_{3} / \mathrm{p}-\mathrm{Ge}$ in this work. method, ${ }^{16}$ in agreement with the finding of Di et al. ${ }^{39}$ The band gap value for $\mathrm{GeO}_{2}$ compares to Lange et al., ${ }^{40}$ where the optical band gap has been measured from an increase of the absorption edge and found to vary from $5.21 \mathrm{eV}$ to $5.95 \mathrm{eV}$, depending on $\mathrm{O}_{2}$ flow rate during reactive $\mathrm{DC}$ magnetron sputtering deposition. The band gap of $5.95 \mathrm{eV}$ refers to highest $\mathrm{O}_{2}$ flow and polycrystalline films of $\mathrm{GeO}_{2}$. The band gap of $\mathrm{GeO}_{2}$ of $\sim 6.0 \mathrm{eV}$ has been reported from SE measurements from absorption edge. ${ }^{41}$ The band gap value of $\mathrm{Tm}_{2} \mathrm{O}_{3}$ compares to $5.76 \mathrm{eV}$ reported from optical reflectance on $\mathrm{Tm}_{2} \mathrm{O}_{3} / \mathrm{Si}$ stack. ${ }^{13}$ It is worth noting a pronounced absorption (at $\sim 5.3 \mathrm{eV}$ ) below the band edge for the $\mathrm{Tm}_{2} \mathrm{O}_{3} /$ Ge, and an Urbach tail (see inset of Fig. 3(d)) as a signature of the poly-crystalline nature ${ }^{42}$ of the thulium oxide film.

The polycrystalline nature of the $\mathrm{Tm}_{2} \mathrm{O}_{3}$ deposited on Ge is directly seen from the HRTEM image and the electron diffraction pattern of Figs. 4(a) and 4(b) from which the cubic $\mathrm{Tm}_{2} \mathrm{O}_{3}$ structure has been identified. What is noticeable from the HRTEM image is the direct and sharp interface between the projected atomic structures of $\mathrm{Ge}$ and the $\mathrm{Tm}_{2} \mathrm{O}_{3}$ film (see white arrows in Fig. 4(b)), which is not the case for $\mathrm{Tm}_{2} \mathrm{O}_{3}$ deposited on $\mathrm{Si}$, where a thin amorphous interfacial layer is observed (not shown). This feature is common to RE oxide or RE oxide-based films. ${ }^{43-45}$ Some roughness is observed at this interface. From the chemical point of view, there is a transition region between the $\mathrm{Ge}$
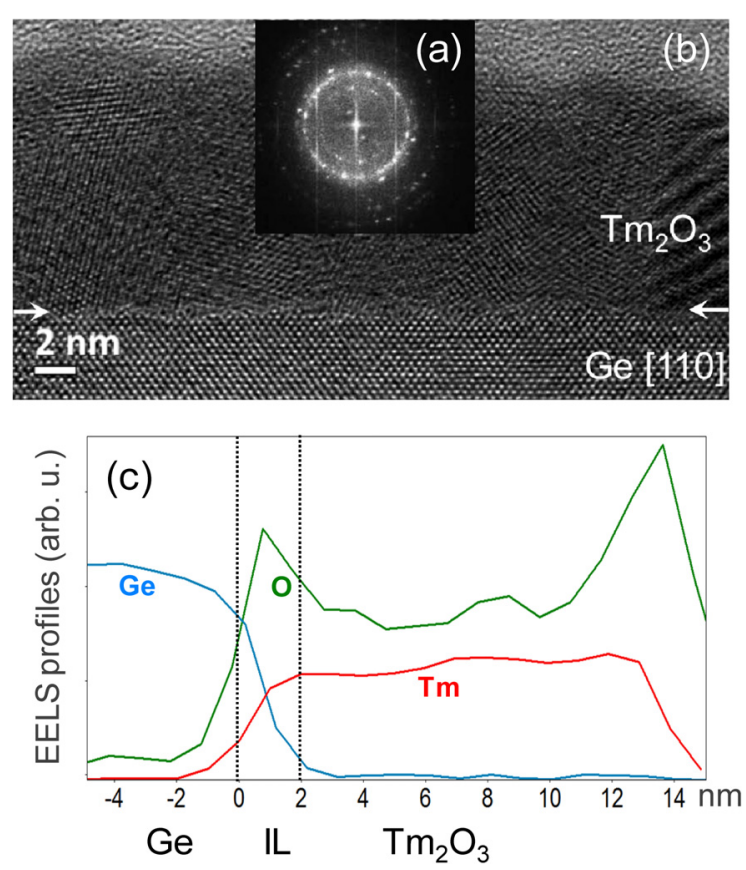

FIG. 4. Electron diffraction pattern (a), HRTEM image (b), and derived EELS elemental profiles across the interface (c), for $10 \mathrm{~nm}$ (nominal) $\mathrm{Tm}_{2} \mathrm{O}_{3}$ on $\mathrm{Ge}$ (white arrows in (b) help to locate the interface). 
substrate and the $\mathrm{Tm}_{2} \mathrm{O}_{3}$ film, where the three elements $\mathrm{Tm}$, $\mathrm{O}$, and $\mathrm{Ge}$ are present, as can be observed from calculated EELS elemental profiles in Fig. 4(c). Due to the $1 \mathrm{~nm}$ probe used for the EELS analysis, the transition region may point out to the roughness of this interface observed at the nanometer level and possibly to a chemically modified interface, at the sub-nanometer level, germanate in nature (Tm-O-Ge). The latter is further substantiated by the presence of a negligible IL peak $(<3 \%$ area) from microscopic XPS measurements of Ge 3p CL shown in Fig. 1(d).

\section{SUMMARY}

In summary, a consistent valence band offset value of $\sim 3 \mathrm{eV}$ has been obtained for atomic-layer deposited $\mathrm{Tm}_{2} \mathrm{O}_{3} /$ Ge from core-level and valence band XPS spectra measured at different sputtering times from a single bulk oxide layer. This method allows for more authentic probing of the interface, as there is no variation introduced when fabricating three separate samples for the XPS measurements. Furthermore, this study points unambiguously to both $\mathrm{Tm}_{2} \mathrm{O}_{3} / \mathrm{Ge}$ and $\mathrm{GeO}_{2} / \mathrm{Ge}$ exhibiting sufficient conduction band offsets $(>1.5 \mathrm{eV})$ to adequately suppress leakage current in real applications. The barrier role of $\mathrm{Tm}_{2} \mathrm{O}_{3}$ interlayer could suppress the growth of unstable $\mathrm{GeO}_{\mathrm{x}}$ and bring effective passivation route in future Ge-based scaled CMOS devices.

\section{ACKNOWLEDGMENTS}

The work was funded by the EPSRC Grant No. EP/ 1012907/1, United Kingdom, and the European Research Grant 228229 OSIRIS. The VUV-VASE experiments were done at J.A. Woollam Co. Inc., NE, USA, courtesy of J. N. Hilfiker. The research leading to HRTEM/EELS results has received funding from the European Union Seventh Framework Programme under Grant Agreement No. 312483-ESTEEM2. M.A. acknowledges support from the Physics Department, Taif University, Saudi Arabia.

${ }^{1}$ K. Choi, T. Ando, E. Cartier, A. Kerber, V. Paruchuri, J. Iacoponi, and V. Narayanan, ECS Trans. 53(3), 17 (2013).

${ }^{2}$ S. Takagi, R. Zhang, and M. Takenaka, Microelectron. Eng. 109, 389 (2013).

${ }^{3}$ R. Zhang, W. Chern, X. Yu, M. Takenaka, J. L. Hoyt, and S. Takagi, Proc. IEEE IEDM Tech. Dig. 2013, 633.

${ }^{4}$ K. Prabhakaran and T. Ogino, Surf. Sci. 325, 263 (1995).

${ }^{5}$ M. Kobayashi, G. Thareja, M. Ishibashi, Y. Sun, P. Griffin, J. McVittie, P. Pianetta, K. Saraswat, and Y. Nishi, J. Appl. Phys. 106, 104117 (2009).

${ }^{6}$ C. H. Lee, C. Lu, T. Tabata, W. F. Zhang, T. Nishimura, K. Nagashio, and A. Toriumi, Proc. IEEE IEDM Tech. Dig. 2013, 40.

${ }^{7}$ S. Sioncke, H. C. Lin, A. Delabie, T. Conard, H. Struyf, S. De Gendt, and M. Caymax, ECS J. Solid State Sci. Technol. 1(3), P127 (2012).

${ }^{8}$ M. Kouda, T. Kawanago, P. Ahmet, K. Natori, T. Hattori, H. Iwai, K. Kakushima, A. Nishiyama, N. Sugii, and K. Tsutsui, J. Vac. Sci. Technol. B 29(6), 062202 (2011).

${ }^{9}$ M. Kouda, K. Kakushima, P. Ahmet, K. Tsutsui, A. Nishiyama, N. Sugii, K. Natori, T. Hattori, and H. Iwai, Jpn. J. Appl. Phys. 50(10), 10PA04 (2011).

${ }^{10}$ T. Ji, J. Cui, Z. B. Fang, T. X. Nie, Y. L. Fan, X. L. Li, Q. He, and Z. M. Jiang, J. Cryst. Growth 321, 171 (2011).
${ }^{11}$ H. Iwai, S. Ohmi, S. Akama, C. Ohshima, A. Kikuchi, I. Kashiwagi, J. Taguchi, H. Yamamoto, J. Tonotani, Y. Kim, I. Ueda, A. Kuriyama, and Y. Yoshihara, Proc. IEEE Int. Electron Devices Meet. 2002, 625.

${ }^{12}$ J. J. Wang, Z. B. Fang, T. Ji, W. Y. Ren, Y. Y. Zhu, and G. He, Appl. Surf. Sci. 258, 6107 (2012).

${ }^{13}$ J. Wang, T. Ji, Y. Zhu, Z. Fang, and W. Ren, J. Rare Earth 30, 233 (2012).

${ }^{14}$ E. Dentoni Litta, P.-E. Hellstrom, C. Henkel, S. Valerio, A. Hallen, and M. Ostling, J. Electrochem. Soc. 160(11), D538 (2013).

${ }^{15}$ E. Dentoni Litta, P-E. Hellström, C. Henkel, and M. Östling, IEEE Trans. Electron Devices 60(10), 3271 (2013).

${ }^{16}$ I. Z. Mitrovic, M. Althobaiti, A. D. Weerakkody, N. Sedghi, S. Hall, V. R. Dhanak, P. R. Chalker, C. Henkel, E. Dentoni Litta, P.-E. Hellström, and M. Östling, Microelectron. Eng. 109, 204 (2013).

${ }^{17}$ W. F. Zhang, T. Nishimula, K. Nagashio, K. Kita, and A. Toriumi, Appl. Phys. Lett. 102, 102106 (2013).

${ }^{18}$ L. Lin, K. Xiong, and J. Robertson, Appl. Phys. Lett. 97, 242902 (2010).

${ }^{19}$ M. Yang, R. Q. Wu, Q. Chen, W. S. Deng, Y. P. Feng, J. W. Chai, J. S. Pan, and S. J. Wang, Appl. Phys. Lett. 94, 142903 (2009).

${ }^{20}$ M. Perego, G. Scarel, M. Fanciulli, I. L. Fedushkin, and A. A. Skatova, Appl. Phys. Lett. 90, 162115 (2007)

${ }^{21}$ Y. Fukuda, Y. Yazaki, Y. Otani, T. Sato, H. Toyota, and T. Ono, IEEE Trans. Electron Devices 57(1), 282-7 (2010).

${ }^{22}$ P. Broqvist, J. F. Binder, and A. Pasquarello, Appl. Phys. Lett. 98, 129901 (2011); P. Broqvist, J. F. Binder, and A. Pasquarello, Appl. Phys. Lett. 94, 141911 (2009).

${ }^{23}$ P. Broqvist, J. F. Binder, and A. Pasquarello, Microelectron. Eng. 88, 1467-1470 (2011).

${ }^{24}$ R. Puthenkovilakam and J. P. Chang, J. Appl. Phys. 96, 2701 (2004).

${ }^{25}$ M. Perego and G. Seguini, J. Appl. Phys. 110, 053711 (2011).

${ }^{26}$ E. Bersch, M. Di, S. Consiglio, R. D. Clark, G. J. Leusink, and A. C. Diebold, J. Appl. Phys. 107, 043702 (2010).

${ }^{27}$ O. Engstrom, J. Appl. Phys. 112, 064115 (2012).

${ }^{28}$ M. Perego, A. Molle, and G. Seguini, Appl. Phys. Lett. 101, 211606 (2012).

${ }^{29}$ E. Kraut, R. Grant, J. Waldrop, and S. Kowalczyk, Phys. Rev. Lett. 44, 1620 (1980).

${ }^{30}$ S. A. Chambers, T. Droubay, T. C. Kaspar, and M. Gutowski, J. Vac. Sci. Technol. B 22, 2205 (2004).

${ }^{31}$ M. T. Anthony, in Spectrometer Calibration; Practical Surface Analysis by Auger and X-ray Photoelectron Spectroscopy, edited by D. Briggs and M. P. Seah (Wiley, New York, 1988), p. 429.

${ }^{32}$ J. C. Vickerman, Surface Analysis (John Wiley, 1998).

${ }^{33}$ D. A. Shirley, Phys. Rev. B 5, 4709 (1972).

${ }^{34}$ R. J. Cole, D. A. C. Gregory, and P. Weightman, Phys. Rev. B 49(8), 5657 (1994).

${ }^{35}$ J. S. Hovis, R. J. Hamers, and C. M. Greenlief, Surf. Sci. 440, L815 (1999).

${ }^{36}$ T. Sasada, Y. Nakakita, M. Takenaka, and S. Takagi, J. Appl. Phys. 106, 073716 (2009).

${ }^{37}$ A. Dimoulas, P. Tsipas, A. Sotiropoulos, and E. K. Evangelou, Appl. Phys. Lett. 89, 252110 (2006).

${ }^{38}$ M. K. Hudait, Y. Zhu, D. Maurya, S. Priya, P. K. Patra, A. W. K. Ma, A. Aphale, and I. Macwan, J. Appl. Phys. 113, 134311 (2013).

${ }^{39}$ M. Di, E. Bersch, A. C. Diebold, S. Consiglio, R. D. Clark, G. J. Leusink, and T. Kaack, J. Vac. Sci. Technol. A 29(4), 041001 (2011).

${ }^{40}$ T. Lange, W. Njoroge, H. Weis, M. Beckers, and M. Wuttig, Thin Solid Films 365, 82 (2000).

${ }^{41}$ C. H. Lee, T. Tabata, T. Nishimura, K. Nagashio, K. Kita, and A. Toriumi, ECS Trans. 19, 165 (2009).

${ }^{42}$ F. L. Martinez, M. Toledano-Luque, J. J. Gandia, J. Carabe, W. Bohne, J. Rohrich, E. Strub, and I. Martil, J. Phys. D: Appl. Phys. 40, 5256 (2007).

${ }^{43}$ L. Lamagna, C. Wiemer, M. Perego, S. N. Volkos, S. Baldovino, D. Tsoutsou, S. Schamm-Chardon, P. E. Coulon, and M. Fanciulli, J. Appl. Phys. 108, 084108 (2010).

${ }^{44}$ S. Schamm-Chardon, P. E. Coulon, L. Lamagna, C. Wiemer, S. Baldovino, and M. Fanciulli, Microelectron. Eng. 88, 419 (2011).

${ }^{45} \mathrm{~S}$. Schamm-Chardon, in Transmission Electron Microscopy in MicroNanoelectronics, edited by A. Claverie and M. Mouis (John Wiley and Sons, New York, 2013), p. 135. 